\title{
Views of health system policymakers on the role of research in health policymaking in Israel
}

Moriah E. Ellen ${ }^{1,2,3,4^{*}}$, Einav Horowitz², Sharona Vaknin² and John N. Lavis Li, $, 6,7,8^{2}$

\begin{abstract}
Background: The use of research evidence in health policymaking is an international challenge. Health systems, including that of Israel, are usually characterized by scarce resources and the necessity to make rapid policy decisions. Knowledge transfer and exchange (KTE) has emerged as a paradigm to start bridging the "know-do" gap. The purpose of this study was to explore the views of health system policymakers and senior executives involved in the policy development process in Israel regarding the role of health systems and policy research (HSPR) in health policymaking, the barriers and facilitators to the use of evidence in the policymaking process, and suggestions for improving the use of HSPR in the policymaking process.

Methods: A survey and an interview were verbally administered in a single face-to-face meeting with health system policymakers and senior executives involved in the policy development process in Israel. The data collection period was from July to October 2014. The potential participants included members of Knesset, officials from Israel's Ministry of Health, Ministry of Finance, health services organizations, and other stakeholder organizations (i.e., National Insurance Institute). The close-ended questions were based on previous surveys that had been conducted in this field. Interviews were tape recorded and transcribed. Descriptive statistics were conducted for close ended survey-questions and thematic analysis was conducted for open-ended interview questions.
\end{abstract}

Results: There were 32 participants in this study. Participants felt that the use of HSPR helps raise awareness on policy issues, yet the actual use of HSPR was hindered for many reasons. Facilitators do exist to support the use of HSPR in the policymaking process, such as a strong foundation of relationships between researchers and policymakers. However, many barriers exist such as the lack of relevance and timeliness of much of the currently available research to support decision-making and the paucity of funding to support research use. Suggestions to improve the use of HSPR focused on improving dissemination of research findings and ensuring that the research was more relevant and timely.

Conclusions: This research demonstrated that health systems policymakers in Israel perceive having strong relationships and collaborations with researchers however there is room for improvement, e.g. partnering in research projects to ensure relevance and use. Furthermore, health system policymakers seem to be interested in receiving relevant research in a more useable format and are open to using research in decision making.

Keywords: Knowledge transfer and exchange, Policymaker, Evidence informed policymaking

\footnotetext{
* Correspondence: moriah.ellen@gmail.com

'Jerusalem College of Technology, Ha-Va'ad ha-Le'umi St 21, Jerusalem

93721, Israel

${ }^{2}$ Israeli Center for Technology Assessment in Health Care, Gertner Institute,

Chaim Sheba Medical Center, Tel Hashomer 52621, Israel

Full list of author information is available at the end of the article
} 


\section{Background}

There is international awareness about the need to bridge the gap between research, practice and policy [1-6]. For close to a decade calls have been made to implement initiatives that link research to action. Knowledge transfer and exchange (KTE) has emerged as a paradigm to start bridging the "know-do" gap [7]. KTE is defined as "a dynamic and iterative process that includes synthesis, dissemination, exchange and ethically-sound application of knowledge to improve the health of [citizens], provide more effective health services and products and strengthen the health care system" [8]. While there are some excellent examples of effective links between research and decision making [9-11], there are still many challenges in using health systems and policy research to inform policy.

One of the main challenges that countries face in KTE is developing and using effective strategies to promote the use of research in policymaking $[12,13]$. The two predominant actors in the KTE process are knowledge producers i.e. researchers and academics, and knowledge users i.e., managers and policymakers. Both knowledge producers and knowledge users have initiatives that they can undertake to support the use of research in policymaking. Knowledge producers produce the research, and if the research is not relevant, packaged in ways that highlight decision relevant information or readily accessible when decision makers need it, then the likelihood of decision makers utilizing the research evidence is poor [14-17]. Other barriers also exist to the use of research evidence in policymaking, for example academic research is frequently written in academic jargon and traditional scientific formats, and is not packaged or disseminated in a user-friendly manner $[18,19]$. Numerous initiatives that researchers can undertake to support KTE have been proposed and studied, such as having researchers 'push' the research out through different channels, facilitating the use of research by ensuring that research is more readily available when it is needed and in a form that is easy to use, and utilizing knowledge brokers and other mechanisms to support linkage and exchange [20-22].

Knowledge users, such as policymakers, also have a role to play in the use of research. While research evidence may only be one of many factors within the decision and policy making process, there is an increasing awareness of its value [23]. Health system policymakers are required to make important and costly health system decisions related to the governance, financial, and delivery arrangements that determine whether the right programs, services and drugs get to those who need them [24]. Policymakers need to be open and receptive to evidence informed policymaking and they are integral to setting the climate for research use. Furthermore, if knowledge users do not know how to acquire, assess or apply the research evidence, and if they do not implement infrastructures that support the use of evidence, then the likelihood of using research evidence to inform policymaking will be poor. Lavis et al, and further reiterations of his framework [4, 20, 25], highlight some actions that policymakers can undertake in order to facilitate evidence informed policy making, such as training and implementing decision making processes that support the use of research evidence.

The success of any KTE strategy is dependent on tailoring the approach and initiatives that are implemented to the local context and the barriers and facilitators operating in these contexts [4, 25-27]. Understanding the local context and the views of the main actors in the process can assist in identifying the barriers and facilitators for KTE. Governments and international agencies provide recommendations and implement policies which they claim to be based on the best available evidence at the time. However, studies have shown that in many cases, these recommendations are not based on the best available evidence and there are gaps between the evidence that was available at the time a recommendation was made and the recommended action [28, 29].

While research in the area of KTE and understanding the views of key actors in the process and actual use of research in policymaking has been conducted in Canada, some Arabic countries, and elsewhere, [3, 13, 23, 30, 31], minimal work has been done in this area in Israel. The use of research evidence in health policymaking is an international challenge. Health systems, including that of Israel, are usually characterized by scarce resources and the necessity to make rapid policy decisions. The Israeli health system is based on the national health insurance (NHI) law, instituted in 1995, that provides every Israeli resident with a basic package of health care, i.e. universal health coverage. The main components of the Israeli health system are the Ministry of Health $(\mathrm{MOH})$, four health insurance funds and other non-profit organizations. The $\mathrm{MOH}$ has overall responsibility for the health of the population and the effective functioning of the health care system. The system is financed through taxation linked to income and accounts for approximately $8 \%$ of the GDP $[32,33]$. In Israel, the high level policy makers (e.g., the Minister of Health) change frequently and may be limited in their knowledge or experience with certain health policy and system issues. However, those that support policymakers and senior executives involved in the policy development process in Israel, have the organizational memory, remain in their post for longer periods of time, and can support KTE initiatives and incorporate HSPR to inform policy. Due to the fact that policymakers are changing often, the culture and processes need to be implemented to support KTE and the approach to KTE and HSPR needs to be suitable to 
both policymakers, those that support policymakers, and senior executives involved in the policy development process in Israel.

Additionally, Israel is a small country with a lot of internal diversity. This means that there may be difficulty in conducting research on policy-type interventions since there can be a problem with the small "sample size" and generalizability. In addition, Israel faces diseconomies of scale; it has just as many national policy issues as much larger countries, but far fewer researchers to study these issues. Thus, it is even more important for researchers and policy makers to be more coordinated, and also be able to use research from other countries as a basis, that can then be assessed, adapted and applied to the Israeli context.

Previous research has been published that examines the experiences related to KTE in Israel of researchers who have conducted health systems and policy research in Israel. Most researchers that conduct health systems research in Israel are based either in research institutes, academic institutions, government agencies, the four health insurance funds, or hospital settings, and many researchers have cross appointments in a number of the aforementioned institutions. This previous research has demonstrated that less than half of the respondents were involved in various KTE activities such as interacting with knowledge users throughout the research process and developing reports and summaries that used language appropriate for their target audiences [34]. More than a third of the researchers in Israel reported that they were frequently or always involved in interactions with target audience through the research process (i.e. during developing a research question or executing the research) or through formal or informal meetings during conferences, workshops or conversations. However, less than half of the researchers stated that they were engaged in bridging activities aimed to facilitate target audiences to use research [34]. While there is engagement from the researchers in Israel, it is important to note that health system researchers are only one part of the equation when it comes to ensuring the use of research in health policymaking. Policymakers in the health system also play an important role in the use of research evidence to inform their decisions. Previous research in Israel has documented the reforms made to the health system as well as the potential role of data to inform policymaking. While the research did demonstrate that data use increased over time and decision makers did rely on data, at times key data were missing and furthermore, the policymakers rarely explored in a systematic way how data could contribute to the decisions they face. In addition, one study found that even where the intention may be to use data to inform policymaking, political motives are also a strong force $[35,36]$. The purpose of this research was to explore the views of health system policymakers and senior executives involved in the policy development process in Israel regarding the role of health systems and policy research (HSPR) in health policymaking, the barriers and facilitators to the use of evidence in the policymaking process, and suggestions for improving the use of HSPR in the policymaking process.

\section{Methods}

A survey and an interview were verbally administered in a single face-to-face meeting with health system policymakers and senior executives involved in the policy development process in Israel policymakers in Israel.

\section{Study population}

The survey population consisted of Israeli health services policy makers. This definition included those who are involved directly in health policy making as well as those who support these processes (i.e.: those who consult with policy makers or support them with relevant information such as CEOs, managers or heads of different governmental departments and councils). Individuals who fit these criteria and who were involved in the last five years in at least one health policymaking process in the Israeli health system, were eligible to participate.

\section{Selecting the sample}

It was estimated that there are approximately 60 individuals who can be considered to be health services policymakers or in support roles for these policymakers in Israel. Therefore it was decided that all potential participants will be invited to take part in the survey. The list of potential participants was identified through four main avenues: 1) searching publicly available web sites (e.g.: Israel's Ministry of Health) to identify individuals in appropriate positions, 2) consulting with leaders in the health policy arena who are familiar with the health policy making landscape in Israel, 3) contacting the National Institute for Health Policy to determine if they could identify additional participants, and finally, 4) using a respondent-driven sampling technique (i.e., asking participants at the completion of the interview if they can identify any additional participants that may have relevant information for our study). The sampling frame was purposefully broad to ensure that all potential participants were captured: therefore the survey may have been applicable to a smaller number of participants than what was sent out.

The final list of potential participants included officials from the following: the Knesset, Israel's Ministry of Health (CEO, heads of divisions and departments, deputy directors and heads of national councils); Ministry of Finance; health services organizations (CEOs and vice 
presidents); and other organizations (medical centers Hospitals CEOs, National Insurance Institute of Israel's CEO, Israel Medical Association; members of the Knesset).

\section{Developing the survey and interview guide}

The survey was based on a survey that has been tested and has shown high internal consistency and good face and content validity [37], which itself formed the basis of other surveys that have been conducted in this field $[3,30]$. However, this version was lengthy and was therefore modified and adapted to the Israeli context. The survey tool focused on: a) factors that have an effect on the health policy making process, b) barriers to use HSPR by policy makers, c) linkage and exchange activities between researchers and decision makers/policy makers, and d) views on KTE $[3,13]$. The surveys consisted of a demographics section and closed ended questions, with response options on quantitative scales. The response options to the quantitative scales were given on ordinal scale ranging from 1 to 5 (were: 1 = "strongly disagree" and $5=$ "strongly agree") with a middle neutral category $(3=$ "neither agree nor disagree"). The interviews consisted of open ended questions that focused on the barriers and facilitators to using evidence to inform policymaking and suggestions to improve the usage of HSPR as part of the policy making process.

The survey and interview tools were translated into Hebrew using the process recommended by the World Health Organization [38]. First, the tools were forward translated to Hebrew by a researcher familiar with the terminology of the area covered by the survey and interview. Second, the tools were back translated to English by an independent translator whose mother tongue is English. Third, both versions (English and Hebrew) were given to a bilingual expert in order to resolve the inadequate expressions/concepts of the translation. Finally, the Hebrew translation was corrected to its final version.

\section{Recruiting the sample and administering the survey and interview}

An initial email, in Hebrew, was sent out to all potential participants inviting them to participate in the study. The letter described the purpose of the study and offered the recipients the opportunity to participate voluntarily in the study and contribute based on their experience. Recipients were also told that the survey and interview can take place at their work place or another location that is convenient for them. A second reminder was sent two weeks after the initial request, followed by a third reminder which was sent a month later. Those who did not respond to the third reminder were contacted by phone.
Both the survey and the interview were conducted in a single face-to-face meeting and the latter was recorded and transcribed. The interviews took place at the location most convenient for the participants, which most often was their workplace. Participants were asked to sign a consent form and were assured that all responses would be anonymized. The data collection period was approximately four months (July to October 2014).

\section{Data analysis}

All the quantitative responses were exported to the Statistical Package for Social Sciences (SPSS) and analyzed using descriptive statistics. Descriptive analyses were conducted for closed-ended questions. For close-ended questions about views on the barriers and facilitators to use HSPR we combined the two highest response options.

The interview data were analysed using a constant comparative method for the thematic analysis. Two researchers independently read and coded the transcripts. First we read the entire interview transcript to get a sense of the whole interview and initial impressions. Then we read the text a second time, coded units of text, and compared initial codes. Coded segments were then re-analysed, coded into subcategories, and compared again.

The study received ethics exemption from the Jerusalem College of Technology's ethics committee.

\section{Results}

A total of 73 potential respondents were contacted; three of them did not meet the criteria for participation in the study. 32 policy makers were surveyed and interviewed (response rate of $46 \%$ ). Non-response was due to the following reasons: 4 refused, 26 did not respond to our initial contact and subsequent letters, and 8 potential respondents agreed to participate but could not commit to an interview during the time frame of study. Among the 32 respondents, 23 were males and 9 females. The average age of the respondents was 54.7 (SD 11.3) years. The age range was 34 to 83 years. The response rate was higher for respondents working for government than for other organizations and the response rate was lower for the ministers, director-generals and CEOs than for other positions. The set of respondents has a greater concentration of government employees, and a lower concetration of top-ranking officials than did the study population. $56 \%$ (18) of participants were from the Ministry of Health, 12.5 \% (4) each from health service organizations and national councils, and the remainder from other organizations such as hospitals, the national insurance institute, the Israel Medical Association, the Ministry of Finance and members of the Knesset. $16 \%$ (5) of the respondents were either Ministers, current or past directorgenerals of the ministry of health, or CEOs, 28 \% (9) of 
the respondents were deputy director-generals or vicepresidents, and $56 \%$ (18) were in other positions i.e., department heads or chairpersons of national committees (see Table 1).

\section{Quantitative analysis of survey questions Views on the role of HSPR in influencing the health policymaking process}

Respondents indicated that there are both significant barriers and important facilitators in the real-world application of HSPR in Israel. Most respondents felt that the use of HSPR was hindered due to practical constraints such as financial implications and just over half felt that it was hindered due to politically sensitive findings (Table 2). About two thirds of respondents agreed that evidence from HSPR does help policymakers identify and/or choose policy alternatives, which reflects and implies an actual use of research, and close to half of the participants stated that evidence from HSPR does help raise awareness on policy issues. Yet, only a quarter of participants felt that evidence was presented to them in a timely manner or in a format that was easily understandable.

\section{Views on the barriers and facilitators for KTE activities}

More than two thirds of the participants felt that the national funding organizations formulated their funding calls in response to regional and national needs and that national funding sources support KTE activities (Table 3). Most participants also agreed that there were structures and processes in place to link them with researchers and that they had the necessary skills to acquire, assess, adapt and apply the

Table 1 Composition of the set of potential respondents compared to the actual respondents by organization type and level in the organization

\begin{tabular}{llll}
\hline & $\begin{array}{l}\text { Potential } \\
\text { Respondents (n) }\end{array}$ & $\begin{array}{l}\text { Actual } \\
\text { Respondents (n) }\end{array}$ & $\begin{array}{l}\text { Response } \\
\text { Rate (\%) }\end{array}$ \\
\hline $\begin{array}{l}\text { Organization Type } \\
\text { Government } \\
\text { (MOH, MOF, etc.) }\end{array}$ & 39 & 20 & $51 \%$ \\
$\begin{array}{l}\text { Non-government } \\
\text { Level in the organization }\end{array}$ & 34 & 12 & $35 \%$ \\
$\begin{array}{l}\text { Ministers, } \\
\text { director-generals, } \\
\text { CEOs }\end{array}$ & 18 & 5 & $28 \%$ \\
$\begin{array}{l}\text { Deputy } \\
\text { director-generals/NPs }\end{array}$ & 17 & 9 & $53 \%$ \\
$\begin{array}{l}\text { Others (includes } \\
\text { department heads, } \\
\text { chairpersons of national } \\
\text { committees and other) }\end{array}$ & 38 & 18 & $47 \%$ \\
\begin{tabular}{l} 
Total \\
\hline
\end{tabular} & 73 & 32 & $44 \%$ \\
\hline
\end{tabular}

Table 2 The role of HSPR and the factors that influence the use of HSPR by health policymakers and stakeholders Israel

\begin{tabular}{|c|c|}
\hline & $\begin{array}{l}\text { Percentage Agree } \\
\text { or Strongly Agree }\end{array}$ \\
\hline $\begin{array}{l}\text { Use of evidence from HSPR in } \\
\text { policy was hindered by practical } \\
\text { constraints to implementation } \\
\text { such as financial implications }\end{array}$ & 91 \\
\hline $\begin{array}{l}\text { Evidence from HSPR does help } \\
\text { health policy makers and stakeholders } \\
\text { to identify and/or choose policy } \\
\text { alternatives }\end{array}$ & 63 \\
\hline $\begin{array}{l}\text { Use of evidence from HSPR in policy } \\
\text { was hindered by findings that were } \\
\text { politically sensitive or were inconsistent } \\
\text { with a policy direction }\end{array}$ & 52 \\
\hline $\begin{array}{l}\text { Evidence from HSPR does help raise } \\
\text { health policy makers and stakeholders' } \\
\text { awareness on policy issues }\end{array}$ & 49 \\
\hline $\begin{array}{l}\text { Use of evidence from HSPR in policy } \\
\text { was hindered by a non- receptive } \\
\text { policy environment }\end{array}$ & 34 \\
\hline $\begin{array}{l}\text { Lack of coordination between policy } \\
\text { makers and researchers hindered the } \\
\text { use of evidence from HSPR in the } \\
\text { health policymaking process }\end{array}$ & 32 \\
\hline $\begin{array}{l}\text { Evidence from HSPR was presented } \\
\text { to policy makers and stakeholders } \\
\text { in a timely manner and in a format } \\
\text { that they can understand }\end{array}$ & 25 \\
\hline
\end{tabular}

relevant research. Less than half of the participants felt that there were significant barriers in place to prevent the use of HSPR. Less than half of respondents felt that organizations that conduct HSPR assisted with KTE activities by making financial and human resources available to assist in the transfer and exchange of knowledge (Table 4). Less than half of the participants felt that the currently available research aligns with the needs of the knowledge users and that the currently available research aligned with the country's priorities (Table 5).

\section{Views of what influences the health policymaking process in Israel}

Most respondents felt that broad challenges in intergovernmental (i.e. Ministry of Health, Ministry of Finance) relations hindered the health policymaking process and more than half felt that broad challenges in government/ provider relations hindered the health policymaking process (Table 6). The four main influencing factors that were perceived to have exerted the strongest influence on the health policymaking process were limited health funding, health insurance funds, the media, and physician associations (Table 7). 
Table 3 Potential facilitators and barriers to the use and implementation and use of KTE activities

\begin{tabular}{|c|c|}
\hline & $\begin{array}{l}\text { Percentage Agree } \\
\text { or Strongly Agree }\end{array}$ \\
\hline \multicolumn{2}{|l|}{ Facilitators: } \\
\hline $\begin{array}{l}\text { National funders formulate their priorities } \\
\text { and calls for proposals in response to } \\
\text { national and regional needs. }\end{array}$ & 78 \\
\hline $\begin{array}{l}\text { National funding sources encourage } \\
\text { KTE activities. }\end{array}$ & 69 \\
\hline $\begin{array}{l}\text { Structures and processes exist to link } \\
\text { you with researchers }\end{array}$ & 68 \\
\hline $\begin{array}{l}\text { Policymakers have access to technical } \\
\text { support for acquiring, assessing, and } \\
\text { applying HSPR research }\end{array}$ & 68 \\
\hline $\begin{array}{l}\text { Funding sources (e.g., granting agencies) } \\
\text { consider KTE activities an allowable expense }\end{array}$ & 65 \\
\hline $\begin{array}{l}\text { Personal and organizational contacts among } \\
\text { policymakers and researchers were quite } \\
\text { stable over time }\end{array}$ & 61 \\
\hline $\begin{array}{l}\text { Policymakers create opportunities to develop } \\
\text { joint HSPR research initiatives with them }\end{array}$ & 45 \\
\hline $\begin{array}{l}\text { Policymakers invest financial and/or human } \\
\text { resources in joint HSPR research initiatives } \\
\text { with them }\end{array}$ & 45 \\
\hline $\begin{array}{l}\text { Policymakers invest financial and/or human } \\
\text { resources in KTE activities }\end{array}$ & 42 \\
\hline \multicolumn{2}{|l|}{ Barriers: } \\
\hline $\begin{array}{l}\text { Priorities in the health system draw attention } \\
\text { away from HSPR research }\end{array}$ & 43 \\
\hline $\begin{array}{l}\text { Policymakers lack the expertise for acquiring, } \\
\text { assessing, and applying HSPR research }\end{array}$ & 31 \\
\hline $\begin{array}{l}\text { Policymakers do not make decisions on the } \\
\text { basis of HSPR research }\end{array}$ & 24 \\
\hline $\begin{array}{l}\text { Policymakers do not have technical access } \\
\text { (i.e. journal subscriptions, links to research) } \\
\text { to the appropriate databases to search for } \\
\text { HSPR research }\end{array}$ & 10 \\
\hline
\end{tabular}

\section{Qualitative analysis of interview questions}

Barriers and facilitators to the use of HSPR in policymaking

The main barrier that was mentioned by all participants related to the lack of timeliness, dissemination, and relevance of the research (Table 8). With respect to the

Table 4 Additional facilitators and barriers at the level of organizational support for KTE activities

\begin{tabular}{|c|c|}
\hline & $\begin{array}{l}\text { Percentage Agree } \\
\text { or Strongly Agree }\end{array}$ \\
\hline $\begin{array}{l}\text { Organizations that conduct HSPR made } \\
\text { available financial and human resources } \\
\text { to assist with KT activities }\end{array}$ & 46 \\
\hline $\begin{array}{l}\text { KT was hampered by a lack of incentives } \\
\text { for KT activities within organization's } \\
\text { that conduct HSPR }\end{array}$ & 15 \\
\hline $\begin{array}{l}\text { Organizations that conduct HSPR were } \\
\text { not seen as a credible source of research }\end{array}$ & 7 \\
\hline
\end{tabular}

Table 5 Alignment of available research to needs of knowledge users

\begin{tabular}{ll}
\hline & $\begin{array}{l}\text { Percentage Agree } \\
\text { or Strongly Agree }\end{array}$ \\
\hline $\begin{array}{l}\text { Available research coincided with my } \\
\text { country's priorities (e.g., with a National } \\
\text { Research Agenda) }\end{array}$ & 48 \\
$\begin{array}{l}\text { Available research coincided with the } \\
\text { needs and expectations of target } \\
\text { audiences }\end{array}$ & 37 \\
$\begin{array}{l}\text { Available research was not considered } \\
\text { relevant by policymakers }\end{array}$ & 11 \\
No research was ready for use & \\
Available research lacked credibility \\
among target audiences
\end{tabular}

dissemination of the research, all participants felt that the research was often not timely and therefore it was frequently not relevant i.e., "there is a kind of delay between the decision making and when you get... the evidence sometimes comes too late, so it, at most, confirms the decisions you already made, but many times there is nothing to rely on". This could be either because of the time it takes to conduct the research, the speed with which decisions need to be made, or the delay between conducting the research and making the research publicly available.

With respect to the actual research, most participants felt that at times, the research was not relevant and did not match the needs of policymakers i.e., "the research does not always answer the question exactly. I mean, it is broader or narrower, it looks from another angle, so it does not always answer the question that arises at the moment." Furthermore, participants felt that many times while there may be research that answers similar questions from other countries, it was not relevant for the Israeli context since Israel's climate, context and culture is different and therefore other country's research cannot easily be adapted. For example, one participant stated that it's "very difficult to rely on policy studies from

Table 6 Factors that influence health policymaking in Israel

\begin{tabular}{ll}
\hline $\begin{array}{l}\text { Broad challenges in intergovernmental } \\
\text { (i.e. Ministry of health, Ministry of Finance) }\end{array}$ & $\begin{array}{l}\text { Percentage Agree } \\
\text { or Strongly Agree }\end{array}$ \\
relations hindered the health policymaking \\
process.
\end{tabular}


Table 7 Groups or factors that exert a strong influence on the health policymaking process

\begin{tabular}{ll}
\hline & $\begin{array}{l}\text { Percentage Agree } \\
\text { or Strongly Agree }\end{array}$ \\
\hline Limited health funding (the economy) & 100 \\
Health insurance funds & 77 \\
Media & 71 \\
Physician associations & 59 \\
Values of governing parties & 41 \\
Public opinion & 38 \\
Other countries' health policies & 36 \\
Nursing associations & 30 \\
Other types of health professional & 20 \\
associations & 19 \\
Research about problems related to & \\
healthcare or health systems & 3 \\
Donor organizations &
\end{tabular}

countries that have a completely different health system [...]. So the adaptations we need to make are very complex, which makes the research not always relevant." Many respondents also cited the typically ineffective dissemination methods as a barrier, either in the packaging (i.e., "Sometimes we need a bottom line ... So what are the conclusions and what are the recommendations") or the channel (i.e. academic journals) that the research is disseminated. Another barrier that was mentioned many times was the logistical limitation or inability to make the changes in the organizations.

Some participants felt that the positions taken by different stakeholder groups, such as industry, and the 'political agenda' were barriers. It was felt that "if research does not fit with their (policymakers) perception, so they ignore it". Other participants also felt that policymakers' pre-conceived notions regarding the decision making process and the inclusion of research in that process were major barriers to the use of HSPR in decision

Table 8 Representative quotes on the barriers to the use of HSPR in health policymaking/decision making in Israel ${ }^{a}$

\begin{tabular}{|c|c|}
\hline Theme & Representative quotes \\
\hline $\begin{array}{l}\text { 1. Barriers related to the act } \\
\text { and dissemination of the }\end{array}$ & \\
\hline - The research is not timely & $\begin{array}{l}\text { The time from when the study was conducted until it was published. This is a general problem with } \\
\text { research - it takes too long until they are published and it is unclear that the data is still relevant to current } \\
\text { reality. } \\
\text { One of the problems is that it is very rare that you have the information you want. The problem is you } \\
\text { want to get information, information that you don't have, and do not have time to wait for it. Most of the } \\
\text { studies that I see come after the fact, and this is } 20 / 20 \text { hindsight. }\end{array}$ \\
\hline
\end{tabular}

- The research is not always relevant i.e. [Researchers] don't always ask us what we need to know, what are the issues that interest us, before the research question does not match planning the research. Then they come and say, "Use this," but we do not need it. the need

- Research from other countries is not always applicable

- Concerns regarding the type of research and the quality of research

- Dissemination of the research results

2. The ability to make the change in the organization

3. Interests from different stakeholders (including political agenda)

4. Policymakers' preconceived notions regarding decision making and attitudes towards research

5. Policymakers' understanding of the research
Discrepancies between international research and international data and the situation in Israel Doubts about the relevance of studies and data from overseas to the unique situation in this country, requires self-examination, [that] cannot always be done.

Research where it is not clear what was their methodology... I want to see the methodology of the study to see how much I can trust it, critically, and if I do not have access to the methodology, it makes it difficult for me.

Studies get published but they remain at the level of articles and conferences, but they don't break down into the particulars to examine applicability.

We have a highly structured health system with a particular structure where it is not always easy to implement, to fit some things to the evidence, in a framework where it's very difficult to make changes in the structure of our system.

There are all sorts of considerations for the HMOs in implementing... especially of the doctors and, definitely, of the government.

Barriers of personal views, of politics, the media, the pressures from voters, the wealthy.

Some will adopt this wholeheartedly. If it fits with your doctrine, then it's very good to come out and say "I just happened to find ...".

People have preconceptions about what should be done, no matter what the study shows. The main problem is that policy makers in Israel do not want to make decisions based on data, and certainly in cases where the data do not support their gut feelings, their ideology, their tradition ... don't want to hear, don't want to implement, don't want to internalize it.

Many of the policy makers do not know how to read research ... social research, which is what create policies, add other variables to the picture, variables that doctors don't have a clue. They sometimes do not even realize their importance. 
making. Some participants felt that "policymakers [think they] know everything" and that it has become the norm for decisions to be "based on personal preferences and on the basis of subjective understanding of reality, this is the tradition that exists in Israel."

Finally, it was felt that at times, many different individuals are working on the same issue in such a small country at the same time and there is a "situation in which a lot of people are working on the same thing in parallel without interaction - there is no communication within the Ministry of Health, outside the Ministry of Health, in the HMOs themselves. And that, I would not say "full gas in neutral" but why do we need to use four cars at the same time if you can put them all in the same car so they can go together? Lack of communication between the relevant parties creates a situation where you are sometimes not aware of the existing policy- by the time you are aware of it, you suddenly discover that you are too late. So you say, "I was working on this, I tried to lead something, and in fact it already exists". Because people forget they have to pass on the information on policies". This lack of communication and alignment acts as a barrier to the use of the appropriate information when developing policies.

Most participants felt that the main facilitator to the use of research in policymaking and decision making was the collaboration and relationships between researchers and policymakers (Table 9). Different forms of collaboration were mentioned such as ensuring experts are included in the decision making process i.e., "It's that there is a professional in this decision-making process that is critical. Decision-making is not carried out by those who don't know how to read research." Another form of collaboration was having round tables with the National Institute for Health Policy (NIHP) i.e., "Round tables at the healthcare system level that can be a place for raising needs and requirements. For example, meetings of the NIHP, which happens each year, where they collect number of issues and address them; and those who participate in it include academics, and policy makers, and officials from sick funds, so there is discussion and dialogue within the country."

The next main facilitator that was mentioned was related to the actual research such as ensuring that the research outlines the relevance of the study results to Israel i.e., "Research that relates to the population in Israel is by nature better able to influence policy than general research." Outside pressure from both the public and the media was also viewed as a facilitator to support the use of research in decision making. Some respondents felt that a strong facilitator to the use of research in decision making is the existing culture and that there is a "general approach to try to base decisions on facts." This could be because some decision makers have a background in research and they institute this type of culture in their departments i.e., "People who came from

Table 9 Representative quotes on the facilitators to the use of HSPR in health policymaking/decision making in Israel ${ }^{a}$

\begin{tabular}{ll}
\hline Theme & Quotes to support \\
$\begin{array}{l}\text { 1. Collaboration and relationships } \\
\text { between researchers and policymakers }\end{array}$ & $\begin{array}{l}\text { A small country, where there are many connections between people, so they have many opportunities } \\
\text { for sharing information and transferring ideas etc. That helps... } \\
\text { Since there is the Knesset Research and Information Center, we have a better ground for work on, } \\
\text { because the work is based on data and not only on intuition or biased knowledge that is only based } \\
\text { my life-experience, and I don't know other people's life experiences well enough. } \\
\text { Combination of researchers who are also involved in clinical work, i.e. management, as well as } \\
\text { researchers, who can influence research directions and then get results that fit their decision making. }\end{array}$ \\
$\begin{array}{ll}\text { 2. Facilitators related to the actual research } \\
\text { and dissemination of the research }\end{array}$ \\
$\begin{array}{ll}\text { - Outlining the relevance of the study to } \\
\text { Israel }\end{array}$ \\
$\begin{array}{l}\text { Research that relates to the population in Israel is by nature better able to influence policy than gener } \\
\text { research ... The more it refers to the Israeli population, or a specific sector where the question is, then } \\
\text { its validity would be greater, it will have more weight. } \\
\text { The quality of research - relevant research, done on a large scale, with the participation of relevant } \\
\text { people with prestige and influence on decision makers. } \\
\text { Research based on administrative data is very helpful to rely on, and not only on sample and survey } \\
\text { data. } \\
\text { The quality of research which is reflected ... also the methodology, even where it was published. }\end{array}$
\end{tabular}

3. Outside pressure

- Public pressure

Understanding of the need by the public, so they can come out and demonstrate and influence decision-making

- Media pressure

An increase in the prevalence of the phenomenon as is reflected in the media. Politicians are very sensitive to the media...

4. Culture that supports the use of research in decision-making

The great openness and the desire of decision makers, and their understanding that such studies can be a working tool, or a tool that contributes to decision making. It's this willingness of the decision-makers

${ }^{a}$ The themes in the table are presented from the most to the least common themes mentioned in the interviews 
research ... and create a culture of a kind of decisionmaking in the offices." Another reason for the existence of this culture could be a spill over effect from medicine i.e., there is an accepted culture in medicine of evidence based practice and therefore there is an overall push that all decisions should be based on research i.e., "the medical culture - they use a lot of evidence based. There is a push for research ...".

\section{Main KTE activities in Israel}

All participants mentioned attending both local and international conferences as the main KTE activity in Israel as they serve as a basis for collaboration and future research (Table 10). Most participants mentioned building formal relationships between researchers and policymakers as an important KTE activity in Israel. This included being partners in research production or having formal meetings and collaborations to discuss research i.e., "All the relationships we have with the research institute, which is expressed by raising issues." Another KTE activity that was mentioned was collaboration between researchers and decision makers on committees for specific health system issues such as i.e., wait times and quality improvement.

\section{Suggestions to improve the use of HSPR in health policymaking in Israel}

Most participants felt that in order to improve the use of HSPR in policymaking in Israel, the dissemination of research findings needs to be more effective i.e., "to reach politicians - in order to speak the same language, they need to get it in some kind of a "nutshell", so that they understand the significance and importance ... where it affects them, what benefit it gives them" (Table 11). The research has to be delivered to the policymakers in a manner that is easy to understand and apply. Some respondents recognized that the responsibility falls on both knowledge producers and knowledge users i.e., "Concerning the transfer of information - it's true not only on the side that posts the information, but also on the receiving side. That decision-makers have someone in charge of interactions."

Practical suggestions were provided regarding how to improve the dissemination of research findings i.e.,

- Consolidating the dissemination of findings and either

o developing a website focused on health research that will send emails with list of recent research, associated abstracts and links to the research,

o compiling a quarterly newsletter that highlights recent relevant research, and/or

o providing short summaries of research, not more than 3-5 lines

- Sending concise, targeted emails with links to the research,

- Inviting researchers to present in the decisionmakers' organizations

- Training both knowledge producers and knowledge users on effective dissemination and usage of research findings

- Using knowledge brokers or leaders to disseminate the information

Table 10 Representative quotes of main KTE activities in Israel $^{a}$

\begin{tabular}{|c|c|}
\hline Theme & Quotes to support the theme \\
\hline 1. Attending local and international conferences & $\begin{array}{l}\text { The presence at and support of conferences, which I think are also a good tool to design } \\
\text { future research. Then you report what you have done, but it's actually the infrastructure } \\
\text { for the things that follow. }\end{array}$ \\
\hline \multicolumn{2}{|l|}{$\begin{array}{l}\text { 2. Building formal relationships } \\
\text { between researchers and } \\
\text { policymakers }\end{array}$} \\
\hline - Partners in research production & We're constantly involved in research ... all kinds of researchers come to us. \\
\hline - Meeting to discuss research & $\begin{array}{l}\text { The activities of the Ministry of Health }(\mathrm{MOH}) \text { Management with the Gertner Institute } \\
\text { (Institute for Epidemiology and Health Policy Research), - periodic meetings to talk } \\
\text { about research and what are the needs of the } \mathrm{MOH} \text {, and what Gertner can give. }\end{array}$ \\
\hline $\begin{array}{l}\text { 3. Collaborating on committees } \\
\text { for specific issues }\end{array}$ & $\begin{array}{l}\text { We direct advisory committees in many fields to define quality indicators in hospitals } \\
\text { in Israel and carry out studies of clinical outcomes, form partnerships with relevant } \\
\text { scientific unions, and collaborate in studies they do and conduct our own studies... } \\
\text { for formulating policy, eventually. }\end{array}$ \\
\hline $\begin{array}{l}\text { 4. Linkages with international } \\
\text { organizations i.e. OECD }\end{array}$ & $\begin{array}{l}\text { The MoH representative in the OECD makes the integration of what is happening with } \\
\text { our hospital quality indicators and what is done with quality indicators around the world } \\
\text { and we participate in international studies as part of the OECD countries to make } \\
\text { international comparisons. } \\
\text { Meetings with international bodies such as the OECD, the World Health Organization, } \\
\text { conferences of all sorts. }\end{array}$ \\
\hline
\end{tabular}


Table 11 Suggestions to improve the use of HSPR in health policymaking in Israel ${ }^{a}$

\begin{tabular}{ll}
\hline Topic & Quotes to support \\
\hline $\begin{array}{l}\text { 1. Increased and more effective dissemination } \\
\text { of research findings to policymakers }\end{array}$ & $\begin{array}{l}\text { There should be someone who connects and create this link between policymakers and researchers, } \\
\text { because, in this era of profusion of studies in various fields, we need to have someone to do the } \\
\text { integration before they submit it to policy makers. }\end{array}$
\end{tabular}

You come to the decision maker and show him a study and he has no idea how to judge it, how reliable it is, how valid it is, whether the methodology is correct ...

Need to find form of transferring information that is convenient to policy makers.

Practical ideas re: implementation

Consolidating dissemination of findings:

Once the institute has published something, send it, maybe not every month, but maybe several times a year, every quarter ... you can send abstracts ... and suddenly I see that it's something very interesting to me and that I'm working on at the moment. I may not read it now, maybe l'll print it and read it later..

Some kind of a digest, a site that sends abstracts directed at policy issues, that I can choose from a list of topics.

A quarterly, bi-annual or annual publication that collects all the articles... Whoever wrote an article and thought it is relevant to the field of policy should send it is to this place and they can distribute it as a news-letter once every $X$ time, and you can see all the things that were published, and see if you want to get into it or not. Not every time there is a new study- not something that overwhelm people- but something they know that comes out between 1 and 4 times a year, each time an email. And whoever wants to, can look at it.

Disseminating concise summaries of study findings:

Distributing very concise summaries by e-mail to the target audience. If it's really an abstract- 3-5 lines- I can read it.

Inviting researchers to present in the decision-makers' organizations

Inviting researchers to present their research work within a policy-oriented framework, i.e. to policy makers within the organization, not in an external conference ... for example, a board meeting of the Ministry of Health or our meetings, if a researcher can came to present his work more frequently.

Training both knowledge producers and knowledge users on effective dissemination and usage of research findings:

To train policymakers in using findings efficiently and to train the reviewers on how to correctly present and how to fit the needs of policy makers in the way they pass on the information.

\section{Pushing findings:}

Researcher who conduct a study and has findings should push it. Publish it in all sorts of ways. There are many ways to publish. Pushing knowledge - but pushing is something you do again and again. You sent something and there is no response, you can send it again. Don't be afraid to push, to be a little aggressive in pushing knowledge that seems very important. To push it via e-mail or other kinds of mail, or request an appointment or send it again, or remind them, if the situation arise. Marketing the information, the knowledge, upwards and onwards.

Using knowledge brokers or leaders to disseminate the information:

Research should involve people of reputation and status that may promote this tool called research to decision makers, including knowledge brokers.

Enabling the ability to search in national language i.e. Hebrew

A search engine in Hebrew- that I can have one in Hebrew as well, some place that collects all the studies and then I can search ... something more accessible. It does not have to be only peerreviewed studies, but also documents from Brookdale (Centre for Health Policy Research) and the like...

2. Collaboration between researchers and policymakers on research production

At the stage when they develop research, that it should kind of fit the needs, i.e. to be involved early in the development of research so that it would answer my needs, that someone will take into account issues and methodology that interests me. The researchers will know what is the product that I need.

Building research together with policymakers, in advance- defining the main objective, reaching consensus on its meaning.something that is done in advance together.

Interactions with policy makers in advance to define the questions that interest them and are still unanswered by research. In major issues, you should also consult with them on study design, in a way that will make it more relevant to policymakers. 
Table 11 Suggestions to improve the use of HSPR in health policymaking in Israel (Continued)

\author{
3. Opportunities for official linkage and \\ exchange between policymakers and \\ researchers such as; \\ - Conferences
}

- Journal club/research clubs

\begin{abstract}
If you define in advance the role of decision maker, or an executive; if you make it a part of his roles not only to provide services but also to create an interface with the Academy. So you generate, in advance, an organizational commitment, even a physical one, for the purpose of learning, reading, hearing and cooperation. .
\end{abstract}

Periodic meetings with the NIHP. The Health Ministry has a level that knows what is happening at the $\mathrm{NIHP}$. At my level, which is an intermediate level, we don't know... If there were conferences to the middle levels... to see what you are researching, what you are doing, how it relates.

For me, this whole story of conferences and journal clubs is very helpful, but many policy makers don't see its importance of it and make time.

Periodic meetings - invite various organizations to present their fields of interest to the Health Ministry, the HOMs management, all kinds of decision-makers. There are institutions such as Tel Aviv University, Brookdale (Centre for Health Policy Research), Gertner (Institute for Epidemiology and Health Policy Research), places like this, that can, once in a while, come and present their work in these fields and to see what are the relevant components and where they can augment each other.

Formal meetings. To make some seminar or a consensus conference where policy makers will be invited (usually there are only researchers in such consensus conferences) so a kind of sharing, joint seminar...

4. Increased budget to support KTE Instead of investing 100 NIS in research, spend 90 on research and 10 on implementation...

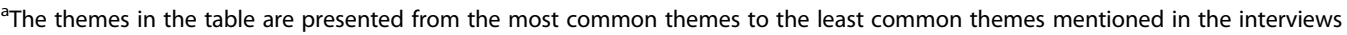

- Enabling the ability to search in the national language i.e. Hebrew

Most participants also stated that increased collaboration between researchers and policymakers on research production can ensure the use of research in decision making i.e. "The academy cannot be completely cut off, if it wants to influence, if it wants to be a part of things, it needs to connect with the decision making process at an earlier stage." Furthermore, providing opportunities for official linkage and exchange between policymakers and researchers can improve the use of research in decision making. These opportunities can occur either at conferences or through research meetings.

However, some participants felt that conferences were not so useful because they are very subject specific, limit the number of participants, and are not accessible to all due to the cost i.e. "At the Dead Sea Conference, for example, they limit both to a specific subject and also to a very small number of people" and "Making it so that the conferences are not so expensive ... or open them, extend more invitations to conferences." Furthermore, some participants felt that conferences were not so useful i.e. "I don't use "they said so at a conference" when I make a policy decision." Additionally, conferences should not be viewed as 'the tool' to disseminate the knowledge since many times they key knowledge users are not present i.e., "Usually the Director General and Deputy Director General and the Minister come, greet and leave. Everyone knows it... How come researchers do not realize that this will not lead to results if the person who needs to hear isn't there ... I'm not saying we should stop having conferences, but it can't be the tool $(8("$ ".

\section{Discussion}

In this study, we investigated the views of health system policymakers' and senior executives involved in the policy development process in Israel on the use of HSPR to inform decision making. Both the quantitative and the qualitative components of the study demonstrated that while there are many barriers in place, there are numerous facilitators that are already in place and support evidence informed policymaking and they can also be capitalized on for future initiatives. The barriers primarily focused on the currently available research and the lack of some of its relevance and timeliness to support decision making, the usually ineffective dissemination of research, and interests of different stakeholder groups. The main facilitator that was identified both in the quantitative and the qualitative research was the strong foundation of relationships and collaborations between researchers and policymakers or decision makers. Participants provided a wealth of suggestions regarding how to improve the use of HSPR to support health policymaking and decision making.

The diversity of respondents can be viewed as both a strength and a limitation of the study- it provides us with a wider context of many of the actors in the policy making process, but, on the other hand, their divergent perspectives and personal experiences can lead to different opinions on the use of HSPR and its role in the policymaking process, thus obfuscating the results. While we may note the differences in response rates for each category of respondents, two issues must be taken into consideration. Firstly, the number of potential respondents in each category is relatively small, especially if we integrate the different categories together (i.e. director level- government, other-non-government, etc.) as well 
as other subdivisions within each category, so that it is likely that potential systematic biases may be overshadowed by the individuality of each respondent's unique position. Secondly, the categorizations was based on the respondents current position, or the one that they held within the previous 5 years- many of the respondents have a long history of different positions within the healthcare system or the policy-making process, therefore their response may reflect experiences and perspectives that place them into more than one category.

The biggest strength of this study is that, to our knowledge, this is the first study examining the views on the use of HSPR by health system policymakers and and senior executives involved in the policy development process in Israel. Further strengths include that the close-ended questions were built on a pre-existing and validated instrument and that the survey was administered face-to-face as opposed to online, thus promoting a somewhat higher response rate. However, our survey is not without limitations. The two main limitations are: a) despite the fact that the researchers went to great lengths and repeated attempts to recruit participants, the response rate is lower than hoped and $b$ ) the survey is based on self-reports and therefore, social desirability bias cannot be excluded. These limitations may influence both internal validity and the generalizability of the findings to the broader population.

Another limitation of the study is that it asked respondents to relate to the research-policy interface overall. It is quite likely that the effectiveness of the interface varies across institutions, policy area, type of research, etc. There may also have been some differences in among various types of respondents in their perceptions; however given the relatively small sample size it is not possible to differentiate the effects of those differences from just individual variability. There are important opportunities for further research to explore what accounts for the variation in the effectiveness interface in Israel; both quantitative studies and in-depth case studies can play an important role.

Some of the findings of this study are in alignment to the findings of other international studies. Similar to other studies, this study identified the need for the timeliness and relevance of the research as well as the local applicability of the research as factors that can influence the uptake of research evidence [15, 39-41]. Furthermore, numerous papers and studies have been written about the importance of relationships and collaboration between researchers and decision makers which can facilitate the increase of evidence informed policymaking. Barriers such as lack of personal contact and opportunities to discuss challenges and research opportunities between researchers and knowledge users impede the use of research in policymaking $[15,17,39,41-44]$. The issues uncovered in this research, while not new in the field of KTE, are new to the Israeli context. These findings provide insight as to the challenges experienced in Israel and provide researchers and decision makers with the necessary evidence to build interventions to support the use of HSPR in policymaking and decision making.

There are some differences as well between this study and the international literature. One main difference is with respect to the groups or factors that exert a strong influence on the health policymaking process. In our study, the three biggest influencing factors were limited health funding, the health insurance funds and the media; however, in other studies, other factors were found to have a strong influence such as physician associations, donor organizations or the values of governing parties $[13,31]$. Furthermore, in two other studies, about half to two-thirds of the respondents agreed or strongly agreed that research about problems related to healthcare or health systems exerted a strong influence on the policymaking process $(46 \%$ in the Eastern Mediterranean Region and $66 \%$ in Canada; the Canadian study focused specifically on research related to healthcare providers), while in our study only $19 \%$ agreed or strongly agreed with that statement $[13,31]$.

Also, based on the quantitative and the qualitative findings, it is apparent that there are strong relationships between researchers and policymakers in Israel. This is in contrast to the situation in many other countries where these relationships appear to be less well developed. For example, in one study from the Eastern Mediterranean region it was found that only $43 \%$ of respondents agreed that there are contact and collaborative relationships between researchers and policymakers and/or decision makers [13]. The relatively strong relationships in Israel should be capitalized upon, as is elaborated below.

Numerous frameworks have been developed, describing an array of initiatives related to KTE, [25, 26, 45-50] yet many of them operate at the individual or clinical level and not at the country level. Lavis et al propose a framework to assist in assessing country level efforts related to KTE and provide insight as to which elements a health system should have in place in order to facilitate the use of research in policymaking [25]. There are seven main elements which are:

1) Climate for research use (i.e. ensuring a climate where researchers, policymakers, and decision makers value the use of research in policy and decision making)

2) Research production (i.e. ensuring appropriate capacity (i.e. financial and human) to conduct highly relevant research)

3) Push Efforts (i.e. efforts undertaken to push the applicable research out to potential users through appropriate channels) 
4) Facilitating Pull Efforts (i.e. ensuring the necessary infrastructure and tools are in place so research can be readily and easily accessible)

5) Pull Efforts (i.e. efforts undertaken by users of research to acquire, assess, adapt and apply the appropriate research)

6) Linkage and exchange efforts (i.e. initiatives to create open relationships and dialogues between the research producers and the research users)

7) Evaluation efforts (i.e. evaluation of KT initiatives).

Based on this research, policymakers in Israel perceive that the linkage and exchange efforts exist in Israel and there is a strong foundation on which to build upon. Strong links between policymakers, stakeholders, and researchers can enhance the transfer of research into practice [51]. Linkage and exchange efforts fundamentally occur when there are positive relationships between research producers and knowledge users, which seems to be the case in Israel [52].

However, policymakers identified the biggest challenges to be within the research production and push efforts. With respect to research production, the quality of the research, its topical relevance, its operational usefulness, the solutions or recommendations associated with the research, and the credibility of the source are all important characteristics that can enhance the use of research in policymaking $[48,53,54]$. Health systems need to ensure that they have the capacity to conduct research and fund the creation of new knowledge [55]. Furthermore, changes are needed so that local stakeholders such as policymakers and decision makers can have influence in determining the nature, quality and applicability of the research being conducted [55]. Ownership of research and research ideas by stakeholders are also important [53]. If the Israeli health system wishes to support the creation of new knowledge that is applicable, future initiatives should focus on establishing regular priority setting processes with researchers, stakeholders, and policy makers, funding new research in the form of partnerships between researchers and knowledge users or health services agencies, and ensuring the overall capacity to conduct or commission research $[20,25,56]$.

With respect to push efforts, ensuring the effective dissemination of research findings is essential. The push efforts that researchers or intermediary groups undertake can bring research evidence about an issue to the forefront and to the attention of policymakers and inform the policy development and implementation processes [12]. The messengers and the packaging of the research are important characteristics to consider [41, 53], and were identified by participants as interventions to consider in improving the dissemination of study findings. Traditionally, researchers disseminate their findings via publications and conferences; these are important initiatives but primarily contain the research findings within academic circles. 'Pushing' the knowledge out to users requires re-packaging of information and highlighting actionable, jargon-free messages [41]. To have an impact, research findings must be translated and adapted to specific contexts and situations [53]. Developing applied products and tools that help knowledge users see the relevance and usefulness of the research is a factor that can affect the successful transfer of research into practice [22, 41, 57]. Examples of push efforts are identifying actionable messages arising from research, fine-tuning the messages for different user groups, working with credible messengers for each group to disseminate the messages, supporting decision making and actions associated with the messages, and developing media releases for the actionable messages, and training researchers to develop their capacity to create, disseminate and execute evidence informed push efforts [25].

What is interesting to note is that most of the areas where policymakers identified a need for improvement fall within the responsibilities of the researchers. Most researchers that focus on health systems and policy research in Israel have acknowledged that they are minimally involved in KTE activities [34]. However, while increasing initiatives both within research production and push efforts to improve the use of HSPR in decision making is important, there are initiatives that can be undertaken by policymakers and decision makers as well.

\section{Conclusion}

This research demonstrated that health systems policymakers in Israel perceive to have strong relationships with researchers; however there is room to improve on these collaborations e.g., partnering in research projects to ensure their relevance. Furthermore, health system policymakers seem to be interested in receiving relevant research in an effective format and are open to using research in decision making. However, providing access to relevant material and assisting target audiences to acquire and use research is rarely done. KTE is a fairly new area in Israel and therefore the level of KTE activities is not very high. Health system and policy researchers in Israel need to be given a deeper understanding of the benefits and potential advantages of KTE in an organized and systematic way and interventions need to be implemented and evaluated to determine the effectiveness in the Israeli context.

\section{Abbreviations}

KTE, Knowledge Transfer and Exchange; HSPR, Health Systems and Policy Research

\section{Acknowledgements}

This study was funded by the Israel National Institute for Health Policy and Health Services Research (NIHP). We would like to thank Avi Israeli for his insight as to the 
design and importance of this study. We would like to acknowledge Assaf Sharon for collecting the data and Haya Grinvald for conducting the statistical analysis.

\section{Authors' contributions}

MEE conceived, designed, coordinated, and conducted the study and wrote the manuscript. EH contributed to the design and the coordination of the study and performed the qualitative analysis as the second researcher. SV contributed to the design of the study and the survey and helped to draft the manuscript. JNL contributed to the conception and design of the study, oversaw the scientific direction, and assisted in drafting the manuscript. All authors read and approved the final manuscript.

\section{Authors' information}

Moriah Ellen, MBA, PhD is a Senior Lecturer in the Jerusalem College of Technology, an investigator at McMaster Health Forum's Impact Lab, and an adjunct professor at the University of Toronto's Institute for Health Policy, Management and Evaluation. Moriah's primary research interests are knowledge translation, health policy and systems, aging and health, and overuse of health services. Dr. Ellen holds an MBA in health services management and marketing from McMaster University, a PhD from the University of Toronto's Institute of Health Policy, Management and Evaluation, and a post-doctorate from McMaster University in the area of health policy.

Einav Horowitz is a senior researcher in the Israeli Center for Technology Assessment in Health Care, in the Gertner Institute. She also works with the Nation List of Health Services Assessment Division of the Medical Technologies \& Infrastructure Administration in the Ministry of Health, conducting Health Technology Assessments of non-pharmaceuticals for the "Health Basket". She has an MD from the Hebrew University and a PhD in Health Systems Administration from the Tel Aviv University. Her areas of expertise are Health Technology Assessments, Cost-Effectiveness Analyses and Health Policy Decision Making.

Sharona Vaknin has a B.Sc. in Biology and an M.Sc in Epidemiology from the School of Public Health of the Sackler School of Medicine in the Tel Aviv University. She works as an epidemiologist and senior researcher in the Israeli Center for Technology Assessment in Health Care in the Gertner Institute, as well as heading the topic of imaging and "High-Cost Technologies" for the Medical Technology and Infrastructure Administration in the Israeli Ministry of Health. Her main areas of work involve techno-epidemiological research of non-pharmaceutical health technology, mainly imaging devices, and she is in charge of the national database for utilization data of "High-Cost Technologies". John N. Lavis, MD PhD, holds the Canada Research Chair in EvidenceInformed Health Systems. He is the Director of the McMaster Health Forum, Co-Director of the World Health Organization (WHO) Collaborating Centre on Evidence-Informed Policy, Associate Director of the Centre for Health Economics and Policy Analysis, Professor in the Department of Clinical Epidemiology and Biostatistics, and Associate Member of the Department of Political Science at McMaster University. He is also Adjunct Professor of Global Health, Department of Global Health and Population, Harvard TH. Chan School of Public Health.

\section{Competing interests}

The authors declare that they have no competing interests.

\section{Author details}

'Jerusalem College of Technology, Ha-Va'ad ha-Le'umi St 21, Jerusalem 93721, Israel. ${ }^{2}$ Israeli Center for Technology Assessment in Health Care, Gertner Institute, Chaim Sheba Medical Center, Tel Hashomer 52621, Israel. ${ }^{3}$ McMaster Health Forum, McMaster University, 1280 Main Street West, Hamilton, ON L8S 4L6, Canada. Institute of Health Policy, Management and Evaluation, University of Toronto, 4th Floor, 155 College St, Toronto, ON M5T 3M6, Canada. ${ }^{5}$ Department of Clinical Epidemiology and Biostatistics, McMaster University, 1280 Main Street West, CRL 209, Hamilton, ON L8S 4K1, Canada. ${ }^{6}$ Department of Political Science, McMaster University, 1280 Main Street West, CRL 209, Hamilton, ON L8S 4K1, Canada. ${ }^{7}$ Centre for Health Economics and Policy Analysis, McMaster University, 1280 Main Street West CRL 209, Hamilton, ON L8S 4K1, Canada. ${ }^{8}$ Department of Global Health and Population, Harvard School of Public Health, Boston, 677 Huntington Ave, Boston, MA 02115-6018, USA.
Received: 14 January 2016 Accepted: 10 June 2016

Published online: 20 June 2016

\section{References}

1. First Global Symposium on Health Systems Research. Montreux Statement from the Steering Committee of the First Global Symposium on Health Systems Research. http://healthsystemsresearch.org/hsr2010/index. php?option=com_content\&view=article\&id=111. Accessed 15 June 2016.

2. El-Jardali F, Ataya N, Jamal D, Jaafar M. A multi-faceted approach to promote knowledge translation platforms in eastern Mediterranean countries: climate for evidence-informed policy. Health Res Policy Syst. 2012;10:15.

3. Lavis JN, Guindon GE, Cameron D, Boupha B, Dejman M, Osei EJ, et al. Bridging the gaps between research, policy and practice in low- and middle-income countries: a survey of researchers. CMAJ. 2010;182:E350-61

4. Ellen ME. Knowledge Translation on Ageing and Health: A Framework for Policy Development. Geneva: World Health Organization; 2012. Ref Type: Electronic Citation.

5. World Health Assembly. Resolution on Health Research. http://www.who. int/rpc/meetings/58th_WHA resolution.pdf.2011. Accessed 15 June 2016.

6. World Health Organization. The Mexico Statement on Health Research: Knowledge for Better Health: Strengthening Health Systems. Geneva: World Health Organization; 2004

7. World Health Organization. Bridging the "Know-Do" Gap. Geneva: WHO Press; 2006.

8. Canadian Institute for Health Information. More About Knowledge Translation at CIHR. http://www.cihr-irsc.gc.ca/e/29418.html. Accessed 15 June 2016.

9. Haynes AB, Weiser TG, Berry WR, Lipsitz SR, Breizat AH, Dellinger EP, et al. A surgical safety checklist to reduce morbidity and mortality in a global population. N Engl J Med. 2009;360:491-9.

10. Levin L, Goeree R, Sikich N, Jorgensen B, Brouwers MC, Easty T, et al. Establishing a comprehensive continuum from an evidentiary base to policy development for health technologies: the Ontario experience. Int J Technol Assess Health Care. 2007;23:299-309.

11. Levin L, Goeree R, Levine M, Krahn M, Easty T, Brown A, et al. Coverage with evidence development: The Ontario experience. Int J Technol Assess Health Care. 2011:27:159-68.

12. Lavis JN. Research, public policymaking, and knowledge-translation processes: Canadian efforts to build bridges. J Contin Educ Heal Prof. 2006; 26:37-45

13. El-Jardali F, Lavis JN, Ataya N, Jamal D, Ammar W, Raouf S. Use of health systems evidence by policymakers in eastern mediterranean countries: views, practices, and contextual influences. BMC Health Services Res. 2012; 12(1):200

14. Lavis JN, Davies HTO, Oxman AD, Denis J-L, Golden-Biddle K, Ferlie E. Towards systematic reviews that inform health care management and policy-making. J Health Serv Res Policy. 2005;10:S1:35-48.

15. Sauerborn R, Nitayarumphong S, Gerhardus A. Strategies to enhance the use of health systems research for health sector reform. Tropical Med Int Health. 1999:4:827-35.

16. Grimshaw JM, Eccles MP, Lavis JN, Hill SJ, Squires JE. Knowledge translation of research findings. Implement Sci. 2012;7:50.

17. Innvaer S, Vist G, Trommald M, Oxman AD. Health policy-makers' perceptions of their use of evidence: A systematic review. J Health Serv Res Policy. 2002;7:239-44.

18. Lavis JN, Wilson M, Grimshaw J, Haynes RB, Hanna S, Raina P, et al. Effects of an evidence service on health-system policy makers' use of research evidence: A protocol for a randomised controlled trial. Implement Sci. 2011;6:51

19. Dobbins $M$, Thomas $H, O^{\prime} B r i e n ~ M A$, Duggan M. Use of systematic reviews in the development of new provincial public health policies in Ontario. Int J Technol Assess Health Care. 2004;20:399-404.

20. Ellen ME, Lavis JN, Ouimet M, Grimshaw J, Bedard PO. Determining research knowledge infrastructure for healthcare systems: a qualitative study. Implement Sci. 2011;6:60.

21. Grimshaw J, Eccles M, Lavis J, Hill S, Squires J. Knowledge translation of research findings. Implement Sci. 2012;7:50.

22. Ellen ME, Lavis JN, Wilson MG, Grimshaw J, Haynes RB, Ouimet M, et al. Health system decision makers' feedback on summaries and tools supporting the use of systematic reviews: a qualitative study. Evid Policy. 2014;10:337-59. 
23. Campbell DM, Redman S, Jorm S, Cooke M, Zwi AB, Rychetnik L. Increasing the use of evidence in health policy: practice and views of policy makers and researchers. Aust New Zealand Health Policy. 2009;6:21.

24. Lavis JN, Posada FB, Haines A, Osei E. Use of research to inform public policymaking. Lancet. 2004;364:1615-21.

25. Lavis JN, Lomas J, Hamid M, Sewankambo NK. Assessing country-level efforts to link research to action. Bull World Health Organ. 2006;84:620-8.

26. Graham ID, Logan J, Harrison MB, Straus SE, Tetroe J, Caswell W, et al. Lost in knowledge translation: Time for a map? J Contin Educ Heal Prof. 2006;26: $13-24$.

27. Nabyonga Orem J, Mafigiri DK, Marchal B, Ssengooba F, Macq J, Criel B. Research, evidence and policymaking: the perspectives of policy actors on improving uptake of evidence in health policy development and implementation in Uganda. BMC Public Health. 2012;12:109.

28. Hoffman SJ, Lavis JN, Bennett S. The use of research evidence in two international organizations' recommendations about health systems. Health Care Policy. 2009;5:66-86.

29. Lavis JN, Ross SE, Hurley JE, Hohenadel JM, Stoddart GL, Woodward CA, et al. Examining the role of health services research in public policymaking. Milbank Q. 2002;80:125-54.

30. El-Jardali F, Lavis J, Ataya N, Jamal D. Use of health systems and policy research evidence in the health policymaking in eastern Mediterranean countries: views and practices of researchers. Implement Sci. 2012;7:2.

31. Lavis JN, Hammill AC, Bourgeault IL, Stoddart GL. The Supply, Distribution and Working Context of Health Professionals: Why Do Things (Almost) Never Change? Hamilton: McMaster University Program in Policy DecisionMaking; 2006

32. Rosen B, Samuel H. Health Systems in Transition. Israel: Health System Review. Edited by Mossialos M, Busse R, Figueras J, McKee M, Saltman R. Volume 11, No 2. 2009. European Observatory on Health Systems and Policies. Ref Type: Report.

33. Chernichovsky D. Not "Socialized medicine"- An Israeli view of health care reform. N Engl J Med. 2009;361:e46

34. Ellen ME, Lavis JN, Sharon A, Shemer J. Health systems and policy research evidence in health policy making in Israel: what are researchers' practices in transferring knowledge to policy makers? Health Res Policy Syst. 2014;12:67.

35. Schwartz R, Rosen B. The politics of evidence-based health policy-making. Public Money Manage. 2004: 121-127.

36. Rosen B, Sicron I, Sykes A, Berg-Warman N, Nirel R, Schwartz R. Data and Decision Making in the NHI Era: A Summary Report. RR-467-06. Israel: MyersJDC-Brookdale Institute; 2006. Ref Type: Report.

37. Cameron D, Lavis JN, Guindon GE, Akhtar T, Becerra-Posada F, Ndossi GD, et al. Bridging the gaps among research, policy and practice in ten low- and middle-income countries: Development and testing of a questionnaire for researchers. Health Res Policy Syst. 2010;8(1):4

38. World Health Organization. Process of translation and adaptation of instruments. http://www.who.int/substance_abuse/research_tools/ translation/en/.2014. Accessed 15 June 2016

39. Lavis JN, Davies H, Oxman AD, Denis JL, Golden-Biddle K, Ferlie E. Towards systematic reviews that inform health care management and policy-making. J Health Serv Res Policy. 2005;10:35-48.

40. Aaserud M, Lewin S, Innvaer S, Paulsen EJ, Dahlgren AT, Trommald M, et al. Translating research into policy and practice in developing countries: A case study of magnesium sulphate for pre-eclampsia. BMC Health Serv Res. 2005; 5:68.

41. Lavis JN, Catallo C, Permanand G, Zierler A, BRIDGE Study Team. BRIDGE Summary 1 - Communicating Clearly: Enhancing Information-Packaging Mechanisms to Support Knowledge Brokering in European Health Systems. Brussels: European Observatory on Health Systems and Policies; 2011.

42. Ellen ME, Leon G, Bouchard G, Lavis JN, Ouimet M, Grimshaw JM. What supports do health system organizations have in place to facilitate evidence-informed decision-making? A qualitative study. Implement Sci. 2013;8:84

43. Ellen ME, Leon G, Bouchard G, Ouimet M, Grimshaw JM, Lavis JN. Barriers, facilitators and views about next steps to implementing supports for evidence-informed decision-making in health systems: a qualitative study. Implement Sci. 2014;9:179.

44. Ellen ME, Brown AD. Transferring research from researchers to knowledge users: the importance of relationships and getting them right. J Health Serv Res Policy. 2015
45. Kitson A, Harvey G, McCormack B. Enabling the implementation of evidence based practice: A conceptual framework. Quality Health Care. 1998:7:149-58.

46. Dobbins M, Ciliska D, Cockerill R, Barnsley J, DiCenso A. A framework for the dissemination and utilization of research for health-care policy and practice. Online J Knowl Synth Nurs. 2002;9:7.

47. Graham ID, Logan J. Innovations in knowledge transfer and continuity of care. Can J Nurs Res. 2004:36:89-103.

48. Jones N, Datta A, Jones H. Knowledge, policy and power: Six dimensions of the knowledge-development policy interface. Overseas Development Institute;2009. Accessed 15 June 2016

49. Nash R, Hudson A, Luttrell C. Mapping Political Context: A Toolkit for Civil Society Organisations. London: Overseas Development Institute; 2006.

50. Rycroft-Malone J, Seers K, Titchen A, Harvey G, Kitson A, McCormack B. What counts as evidence in evidence-based practice? J Adv Nurs. 2004;47:81-90.

51. Moynihan R, Oxman AD, Lavis JN, Paulsen E. Evidence-Informed Health Policy: Using Research to Make Health Systems Healthier. A Review of Organizations that Support the Use of Research Evidence in Developing Guidelines, Technology Assessments, and Health Policy. Report Prepared for the WHO Advisory Committee on Health Research. Oslo: Norwegian Knowledge Centre for the Health Services; 2008.

52. Lomas J. Using 'linkage and exchange' to move research into policy at a Canadian foundation: Encouraging partnerships between researchers and policymakers is the goal of a promising new Canadian initiative. Health Aff. 2000;19:236-40.

53. Nutley S, Walter I, Davies HTO. From knowing to doing: A framework for understanding the evidence-into-practice agenda. Evaluation. 2003:9:125-48.

54. Walter I, Davies HTO, Nutley SM. Increasing research impact through partnerships: Evidence from outside health care. J Health Serv Res Policy. 2003;8:58-61.

55. Bennett S, Agyepong IA, Sheikh K, Hanson K, Ssengooba F, et al. Building the Field of Health Policy and Systems Research: An Agenda for Action. PLoS Med. 2011;8(8):e1001081.

56. Benner PE. From Novice to Expert: Excellence and Power in Clinical Nursing Practice. Menlo Park (CA): Addison-Wesley Pub. Co., Nursing Division; 1984

57. Gold M, Fries Taylor E. Moving research into practice: Lessons from the US Agency for Healthcare Research and Quality's IDSRN program. Implement Sci. 2007;2:9.

\section{Submit your next manuscript to BioMed Central and we will help you at every step:}

- We accept pre-submission inquiries

- Our selector tool helps you to find the most relevant journal

- We provide round the clock customer support

- Convenient online submission

- Thorough peer review

- Inclusion in PubMed and all major indexing services

- Maximum visibility for your research

Submit your manuscript at www.biomedcentral.com/submit 